\title{
Prevention of Fetal Loss in Experimental Antiphospholipid Syndrome by In Vivo Administration of Recombinant Interleukin-3
}

\author{
Pnina Fishman, " Emily Falach-Vaknine," Rosa Zigelman, " Ronit Bakimer," Benjamine Sredni," Meir Djaldetti," \\ and Yehuda Shoenfeld \\ ${ }^{*}$ Hematology Research Unit, Golda Medical Center, Hasharon Hospital, Petach Tiqva, Israel; ${ }^{\ddagger}$ Cancer and AIDS Research Institute, Bar \\ Ilan University, Ramat Gan, 52900 Israel; and ${ }^{\S}$ Research Unit of Autoimmune Diseases, \\ Department of Medicine B, Sheba Medical Center, Tel Hashomer, 52621 Israel
}

\begin{abstract}
Antiphospholipid antibodies are strongly associated with arterial and venous thrombosis and with fetal loss. Recently an experimental model for antiphospholipid syndrome (APLS) was established in our laboratory. In this model, mice are immunized passively or actively with anticardiolipin antibodies and acquire the syndrome, which is characterized by prolonged activated partial thromboplastin time (APTT), thrombocytopenia, low fecundity rate, and fetal loss.

In a normal process of pregnancy, lymphokines affect fetal implantation and development. Cytokines from the colony stimulating factor family, like GM-CSF and IL-3, were shown to be positive signals for implantation and to promote placental development and fetal growth.

Given our preliminary findings of low IL-3 in mice with APLS and the efficacy of IL-3 in preventing fetal loss in a strain of mice prone to fetal resorption, our aim in the present study was to examine the effect of murine recombinant IL-3 (mrIL-3) on pregnant mice induced with experimental APLS. Mice were passively transfused to the tail vein, $24 \mathrm{~h}$ following mating, with anticardiolipin antibodies. The mice were divided into two groups: one group was injected intraperitoneally with mrIL-3 on days 6.5, 8.5, and 10.5 after mating, while the control group was injected with PBS. When the mice were killed on day 15 of pregnancy a $32 \% \pm 4.2$ resorption rate was observed in the anti-cardiolipin-immunized group, which was reduced to $4 \% \pm 0.3$ following treatment with mrIL-3. The thrombocytopenia associated with the experimental APLS was also corrected following lymphokine administration. IL-3 may be effective in prevention of recurrent fetal loss in APLS. (J. Clin. Invest. 1993. 91:1834-1837.) Key words: Antiphospholipid syndrome $\bullet$ cytokines $\bullet$ interleukin-3 $\bullet$ anticardiolipin antibodies - fetal loss
\end{abstract}

\section{Introduction}

Antibodies to the negatively charged phospholipids, particularly anticardiolipin, and lupus anticoagulants, have been

Address correspondence to Prof. Y. Shoenfeld, M. D., Department of Medicine B, Sheba Medicine Center, Tel Hashomer, 52621 Israel.

Received for publication 13 August 1992 and in revised form 12 November 1992.

J. Clin. Invest.

(c) The American Society for Clinical Investigation, Inc.

0021-9738/93/04/1834/04 \$2.00

Volume 91, April 1993, 1834-1837 linked to adverse pregnancy events(1-3). Pregnant women possessing these antibodies have an increased risk for spontaneous abortions, intrauterine fetal growth retardation, preterm birth, and arterial and venous thrombosis. Several mechanisms have been proposed to explain the pathogenicity of the antiphospholipid syndrome in pregnant women, including placental thrombosis and infarction (4), inhibited production of prostacycline $\left(\mathrm{PGl}_{2}\right)$ by blocking the release of arachidonic acid from endothelial cells (5), interference with thrombomodulin (6), tissue plasminogen activator activity (7), protein $S(8)$, or antithrombin III (9).

Recently, two experimental models of antiphospholipid syndrome (APLS) ${ }^{1}$ were established in our laboratory (10-12). In one model, mice were actively immunized with anticardiolipin antibodies and four months later acquired the syndrome characterized by the presence of mouse anticardiolipin antibodies, prolonged activated partial thromboplastin time (APTT), thrombocytopenia, and a low fecundity rate. After mating, they exhibited fetal loss $(10,12)$. In another set of experiments, the APLS model was passively induced by an intravenous transfusion of serum anticardiolipin antibodies ( $24 \mathrm{~h}$ after mating), and similar results were obtained when the mice were mated (11).

In a normal process of pregnancy lymphokines and monokines were found to affect fetal implantation and development (13). Cytokines from the colony stimulating factor family, like GM-CSF and IL-3, were shown to be positive factors for implantation and to promote placental development and fetal growth $(14,15)$.

Following our preliminary findings of inhibited ability of splenocytes to produce IL-3 in mice with experimental APLS (16), and given the efficacy of IL-3 in preventing fetal loss in a strain of mice prone for fetal resorption (14), the aim of the present study was to examine the effect of murine recombinant IL-3 (mrIL-3) on pregnant mice induced with the experimental antiphospholipid syndrome.

\section{Methods}

Mice. 12-wk-old female ICR mice and 14-wk-old males were purchased from the Sackler School of Medicine, Tel Aviv University.

Passive transfer of anticardiolipin antibodies (ACA). 20 female ICR mice were infused on day 1 following mating with $10 \mu \mathrm{g}$ of monoclonal

1. Abbreviations used in this paper: ACA, anticardiolipin antibody; APLS, antiphospholipid syndrome; APTT, activated partial thromboplastin time; CAL, control nonpathogenic anti-cardiolipin antibody; CAR, monoclonal anti-cardiolipin antibody; mrIL-3, murine recombinant IL-3. 
Table I. Effect of Interleukin-3 Therapy on Fetal Resorptions and Hematological Parameters in Mice with Induced Experimental APLS

\begin{tabular}{|c|c|c|c|c|c|c|}
\hline & $\begin{array}{l}\text { No. of } \\
\text { mice }\end{array}$ & $\% \mathrm{R}$ & $\begin{array}{l}\text { No. of } \\
\text { embryos }\end{array}$ & Platelets & WBC & APTT \\
\hline & & & & cells $\times 10^{3} / \mathrm{mm}^{3}$ & cells $/ \mathrm{mm}^{3}$ & \\
\hline Control & 10 & 0 & $14.3 \pm 5$ & $\left.1008 \pm 68]_{*}\right]^{*}$ & $4,100 \pm 500$ & $30 \pm 6]$ * \\
\hline CAR & 10 & $32 \pm 4.21 *$ & $11.0 \pm 0.6]$ * & $847 \pm 30\{*$ & $4,500 \pm 9001$ * & $51 \pm 12]^{*}$ \\
\hline CAR + IL-3 & 10 & $4 \pm 0.3]^{*}$ & $14.8 \pm 0.6$ & $1350 \pm 84]^{*} J$ & $6,140 \pm 700]^{*}$ & $28 \pm 6$ \\
\hline
\end{tabular}

${ }^{*} P<0.05 .{ }^{* *} \mathrm{M} \pm \mathrm{SE}$.

anticardiolipin antibodies through the tail vein as described elsewhere (11).

In vivo treatment with murine recombinant $I L-3(m r I L-3)$. Ten of the ACA-injected mice were treated with mrIL-3 (Cellular Prod. Inc., Buffalo, NY). $200 \mathrm{ng}$ of mrIL-3 were administered intraperitoneally on days $6.5,8.5$, and 10.5 of pregnancy (confirmed by vaginal plug). The other 10 ACA-injected mice served as a control group and were treated with PBS only. Another 10 mice not infused with ACA or IL-3 served as a base line control group.

Evaluation of pregnancy outcome. The number of live embryos per pregnancy and the weights of embryos were studied. The rate of resorptions was calculated as the number of resorbed fetuses $(R)$, divided by resorbed and full-term fetuses $(F)(\% R=R /[R+F])$.

Blood cell counts and coagulation studies. Leukocytes and platelets from individual blood samples drawn on day 15 of pregnancy were counted on an ELT8/WS cell counter (Coulter Electronics Inc., Hialeah, FL). The presence of lupus anticoagulants was evaluated by the prolongation of activated partial thromboplastin time (APTT) in a mixing test adding 1 vol. plasma (whole blood mixed with Na-citrate $0.13 \mathrm{~mol} / \mathrm{liter}$, in a 9:1 ratio), to $1 \mathrm{vol}$. APTT reagent (Sigma Diagnostics, St. Louis, MO) and incubating for $2 \mathrm{~min}$ at $37^{\circ} \mathrm{C}$. Another volume of $0.02 \mathrm{M} \mathrm{CaCl}_{2}$ was added, and the clotting time was recorded in seconds. The results were compared with kaoline clotting time (KCT).

Evaluation of bone-marrow cellularity. Bone marrow cells were withdrawn from the femur of control-, CAR-and IL-3-treated mice on day 15 of pregnancy. The cells were smeared on glass slides, stained with May-Grunwald Giemsa, and differential cell counts were carried out under light microscope.

\section{Results}

The mice injected with the monoclonal anticardiolipin antibodies (CAR) were killed on day 15 . The mice developed a slight thrombocytopenia (mean platelet count of $847,000 / \mathrm{mm}^{3}$ vs. control 1008 $\pm 68, P<0.05)$ and fetal resorption rate of $32 \% \pm 4.2(P<0.0005)$. Following in vivo administration of mrIL-3, thrombocytosis (mean platelet count $1,350,000 / \mathrm{mm}^{3}$, $P<0.0005)$ was observed in the treated mice. The mice given
mrIL-3 showed only $4 \%$ resorptions $(P<0.0005)$ with an increased mean $( \pm \mathrm{SE})$ number of fetuses $(14.3 \pm 0.5$ vs. $11 \pm 0.6, P$ $<0.0005$ ) (Table I). Differential cell count of bone marrow cells revealed a marked increase in the number of megakaryocytes (from 4 to $14 \%, P<0.01$ ) and band forms, indicating a stimulatory effect on the bone marrow. (Table II).

Fig. 1 shows the differences in uterine size and number of fetuses between mice treated with mrIL-3 $(a)$ and the CAR group (b). Several resorptions are seen in the uteruses of those in the anticardiolipin-injected group, while more fetuses are seen in the uterus derived from an mrIL-3 treated animal.

In another group of mice that were sacrificed on day 17 of pregnancy (a regular pregnancy period being 21-23 d), the mrlL-3-treated mice already gave birth, indicating the growth stimulatory effect of IL-3 on embryo size. Fig. 2 shows two representative embryos, one from the mrIL-3 treated mice (right) compared with embryos of untreated control pregnant mice $(l e f t)$.

\section{Discussion}

Implantation and placental development are dependent on two main processes. The first includes a highly proliferative phase of the cytotrophoblast, which is influenced by growth factors produced endogeneously by the trophoblast and later on by the placenta. At the same time, a second process of trophoblast invasion to adjacent tissues like the uterus epithelium, the underlying basement membrane, the connective tissue, and the blood vessels are needed for fetus expansion and growth $(17,18)$. This penetration capability of the trophoblast is due to the proteolytic activity of the enzyme urokinase-type plasminogen activator (19). This enzyme converts the abundant extracellular zymogen plasminogen into plasmin, an active protease that, directly or indirectly, can promote degradation of all components of the extracellular matrix (18).

Table II. Differential Cell Counts of Bone Marrow Cells from Mice Immunized with CAR

\begin{tabular}{|c|c|c|c|c|c|c|c|}
\hline \multirow[b]{3}{*}{ Control } & \multicolumn{7}{|c|}{ Type of cells, $\%$} \\
\hline & Lymphocytes & Monocytes & Neutrophils & Band & Basophils & $\begin{array}{c}\text { Immature } \\
\text { granulocytes* }\end{array}$ & Megakaryocytes \\
\hline & $11 \pm 2.8$ & $4 \pm 1.6$ & $22 \pm 6.3$ & $29 \pm 7.1]$ & $5 \pm 1.3$ & $21 \pm 4.2$ & $8 \pm 2.2$ \\
\hline CAR & $10 \pm 3.2$ & $10 \pm 2.9$ & $30 \pm 11.2$ & $17 \pm 2.8^{J^{+}}$ & $3 \pm 0.2]$ & $26 \pm 9.9$ & $4 \pm 1.2] \pm$ \\
\hline CAR + IL-3 & $8 \pm 1.8$ & $6 \pm 1.1$ & $23 \pm 7.2$ & $31 \pm 9.1$ & $8 \pm 0.9]^{7}$ & $10 \pm 4.2$ & $\left.14 \pm 3.8]^{\mp}\right]$ \\
\hline
\end{tabular}

* Blasts, promyelocytes, metamyelocytes, myelocytes. ${ }^{\ddagger}$ The difference between the two values is significant $(P<0.05)$. 


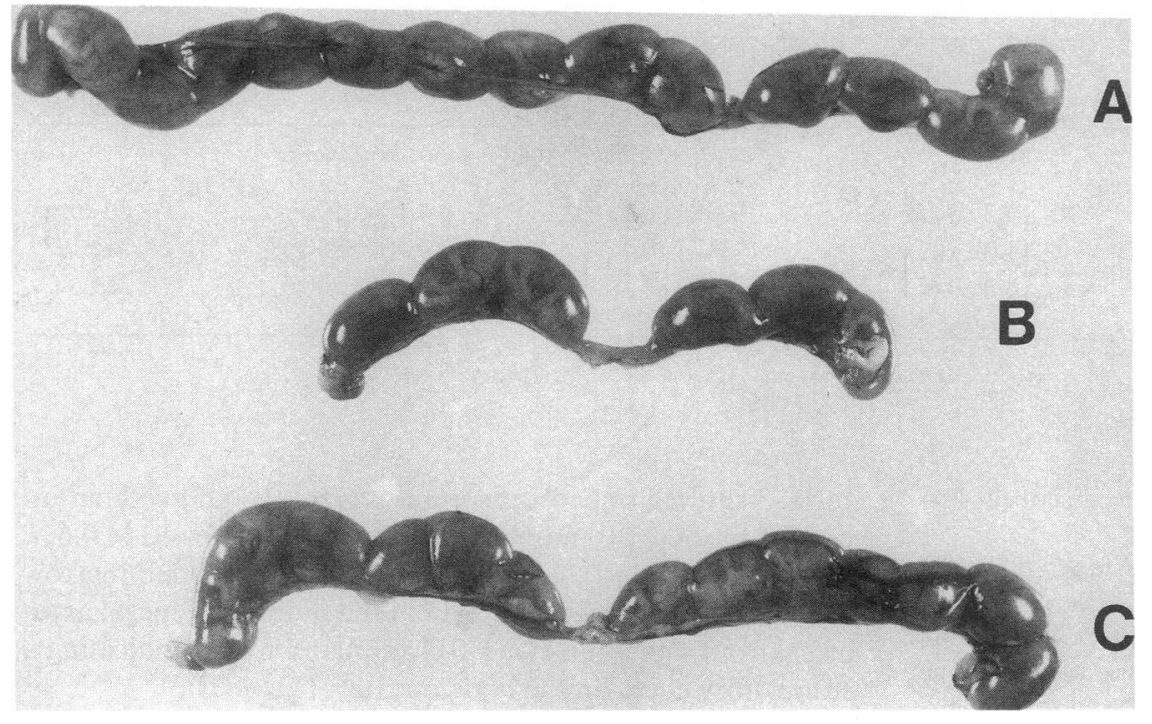

Figure 1. (A). Upper uterus with placenta and fetuses in a mouse infused with anticardiolipin antibodies and treated with mrlL-3 $1 \mathrm{~d}$ after mating. (B). A uterus that was derived from a mouse given anticardiolipin antibody. $(C)$

Uterus from a control mouse. The mice were killed on day 15 of pregnancy.
In the present study, mice induced with APLS by transfusion of anticardiolipin antibodies, developed thrombocytopenia $(P<0.05)$, prolonged APTT $(P<0.05)$ and increased fetal resorption $(P<0.0005)$. In previous studies $(10,11)$ we showed that infusion of nonrelevant monoclonal antibodies and even nonpathogenic anticardiolipin antibody (CAL), were not associated with any of the APLS manifestations. These three parameters, which are characteristic of APLS, were shown to improve following treatment with mrIL-3.

An insight into the broad spectrum of activities of IL-3 reveals that it participates in the two crucial stages responsible for embryo implantation, i.e., trophoblast expansion and trophoblast invasion $(17,20,21)$. IL-3 was shown to play a role in the regulation of placental growth. The proliferation of mouse unfractionated placental cells was stimulated in vitro by the addition of IL-3 (17). The placenta by itself is capable of synthesizing IL-3 as well as G-CSF, M-CSF, and GM-CSF, and thus by an autocrine loop to regulate its own expansion (18). These characteristics of IL-3 may explain its ability to induce fetal development in the APLS-induced mice. Moreover, IL-3 was shown to stimulate the activity of the urokinase-type plasminogen activator of murine bone marrow derived macrophages and peritoneal macrophages following administration in vivo (21)

Francis et al. (7) suggested that a possible mechanism for the pathogenicity of the antiphospholipid antibodies is the ability of these autoantibodies to inhibit plasminogen activator activity. It is reasonable to assume that by its ability to stimulate this enzyme activity, IL-3 can support oval invasion and its subsequent implantation, thus preventing early fetal resorption.

IL-3 is capable of increasing platelet number both in vitro and in vivo, due to a de novo production of megakaryocytes (22-24). The results obtained in the present study indeed indicate an increase in the number of megakaryocytes in the bone marrow followed by peripheral blood thrombocytosis (Table II). Although the exact role of platelets in the pathogenesis of APLS is not yet sufficiently clear, the ability to improve platelet numbers may be a significant clinical finding. In other studies (data not shown) we also examined the effect of low dose aspirin and low molecular heparin on the resorption rates of the experimental APLS. Low dose aspirin decreased the resorption rate from 46 to $11 \%$, while low molecular heparin was effective in reducing the fetal loss from 42 to $12 \%$. IL-3 seems

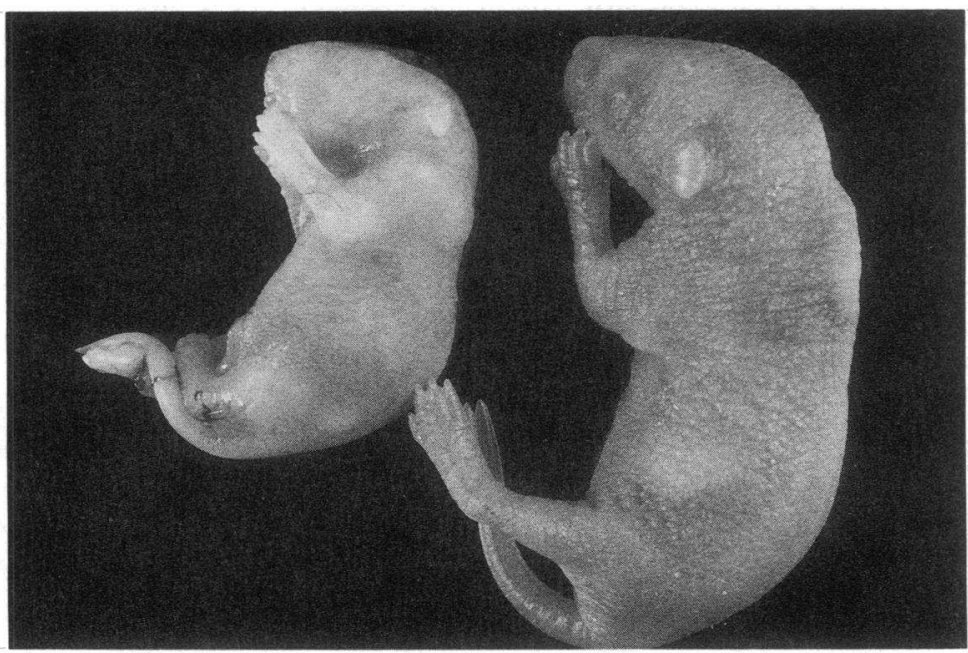

Figure 2. Representative embryos from mice that were immunized with anticardiolipin antibodies $1 \mathrm{~d}$ after mating and killed on day 17 of pregnancy. A marked difference in size between the IL-3 treated mouse (right) and control (left) can be seen. 
to be the most effective of the three modalities, resulting in almost complete abrogation of the fetal loss.

In the present study the monoclonal antibody was infused on day 1, while IL-3 was given on day 6 . Therefore, it seems that the major effects of IL-3 may be targeted either to the advanced stages of blastocysts' maturation or to reversion of the thrombocytopenia. This may suggest that the low platelet number may be a primary event rather than a secondary one.

Human recombinant IL-3, introduced in clinical trials in the last three years, has been shown to exert minimal toxicity and side effects (25-27). The molecule has an impact on the prevention of chemotherapy-induced neutropenia and in the treatment of cytopeniae associated with myelodysplastic syndrome and aplastic anemia $(25,26)$. It would seem that IL-3 represents a novel and unique hemopoietic growth factor that, according to the results obtained in this study, may be effective in the prevention of fetal loss in APLS.

\section{Acknowledgment}

This work was supported by the Basic Foundation Grant, Israel Academy of Sciences.

\section{References}

1. Harris, E. N., A. E. Gharavi, and G. R. V. Huges. 1985. Antiphospholipid antibodies. Clin. Rheum. Dis. 11:591-609.

2. Sammaritano, L. R., A. E. Gharavi, and M. D. Lockshin. 1990. Antiphospholipid antibody syndrome: immunologic and clinical aspects. Semin. Arthritis Rheum. 20:81-96.

3. Alarcon-Segovia, D. and J. Sanchez-Guerrero. 1989. Primary antiphospholipid syndrome. J. Rheumatol. 16:482-488.

4. Brown, H. L. 1991. Antiphospholipid antibodies and recurrent pregnancy loss. Clin. Obst. and Gynecol. 34:17-26.

5. Rustin, M. H., H. A. Bull, S. J. Machin, D. A. Isenberg., M. L. Snaith, and P. M. Dowd. 1988. Effects of the lupus anticoagulant in patients with systemic lupus erythematosus on endothelial cell prostacyclin release and procoagulant activity. J. Invest. Dermatol. 90:744-748.

6. Cariou, R., G. Tobelem, S. Bellucci., J. Soria., C. Soria., J. Maclouf, and J. Caen. 1988. Effect of lupus anticoagulant on antithrombogenic properties of endothelial cells-inhibition of thrombomodulin dependent protein $\mathrm{C}$ activation. Thromb. Haemostasis. 60:54-58.

7. Francis, R. B., W. G. MecGhee, and D. I. Feinstein. 1988. Endothelial dependent fibrinolysis in subjects with the lupus anticoagulant and thrombosis. Thromb. Haemostasis. 39:412-414.

8. Moreb, J., and C. S. Kitchens. 1989. Acquired functional protein S deficiency, cerebral venous thrombosis, and coumarin skin necrosis in association with antiphospholipid syndrome: report of two cases. Am. J. Med. 87:207-210.

9. Cosgriff, T. M., and B. A. Martin. 1981. Low functional and high antigenic antithrombin III level in patient with the lupus anticoagulant and recurrent thrombosis. Arthritis Rheum. 24:94-96.
10. Bakimer, R., P. Fishman, M. Blank, B. Sredni, M. Djaldetti, and Y. Shoenfeld. 1992. Induction of primary antiphospholipid syndrome in mice by immunization with a human monoclonal anticardiolipin antibody $(\mathrm{H}-3)$. J. Clin. Invest. 89:1558-1563.

11. Blank, M., J. Cohen, V. Toder, and Y. Shoenfeld. 1991. Induction of antiphospholipid syndrome in naive mice with mouse lupus monoclonal and human polyclonal anticardiolipin antibodies. Proc. Natl. Acad. Sci. USA. 88:3069-3073.

12. Blank, M., I. Krause, M. Ben-Bassat, and Y. Shoenfeld. 1992. Induction of experimental antiphospholipid syndrome associated with SLE following immunization with human monoclonal pathogenic anti-DNA idiotype. J. Autoimmun. 5:495-509.

13. Wegmann, T. G. 1990. The cytokine basis for cross-talk between the maternal immune and reproductive systems. Curr. Opin. Immunol. 2:765-769.

14. Chaouat, G., E. Menu, D. A. Clark, M. D, M. Minkowski, and T. G. Wegmann. 1990. Control of fetal survival in CBAxDBA/2 mice by lymphokine therapy. Reprod. Fert. 89:447-458.

15. Aihanassakis, I., R. C. Bleackly, V. Paeykau, L. Guilbert, P. J. Barr, and T. G. Wegmann. 1987. The immunostimulatory effect of $T$ cells and $T$ cell lymphokines on murine fetally derived placental cells. J. Immunol. 138:37-42.

16. Fishman, P., R. Bakimer, M. Blank, A. Hohmman, B. Sredni, M. Djaldetti, and Y. Shoenfeld. 1992. The putative role of cytokines in the induction of primary antiphospholipid syndrome in mice. Clin. Exp. Immunol. 514:495-509.

17. Chaouat, G., E. Menue, M. Hofman, M. Dy, M. Minkowski, D. A. Clark and T. G. Wegmann. 1989. Lymphokines at the feto maternal interface affect fetal size and fetal survival. J. Reprod. Immunol. (Suppl.) 34.

18. Lala, P. K., and C. H. Graham. 1990. Mechanisms of trophoblast invasiveness and their control: the role of proteases and protease inhibitors. Cancer $\mathrm{Me}$ tastasis Rev. 9:369-379.

19. Blasi, F., J.-D. Vassalli, and K. Danø. 1987. Urokinase-type plasminogen activator. Proenzyme, receptor, and inhibitors. J. Cell Biol. 104:801-804.

20. Bradley, T. R., E. R. Stanley, and M. A. Sumner. 1971. Factors from mouse tissues stimulating colony growth of mouse bone marrow cells in vivo. Aust. J. Exp. Biol. Med. Sci. 49:595-601.

21. Hamilton, J. A., G. Vairo, K. R. Knight, and B. G. Cocks. 1991. Activation and proliferation signals in murine macrophages. Biochemical signals controlling the regulation of macrophage urokinase-type plasminogen activator activity by colony stimulating factors and other agents. Blood. 77:616-627.

22. Fishman, P., S. Sredni, and M. Djaldetti. 1990. Recent advances in interleukin-3 research. Isr. J. Med. Sci. 26:414-419.

23. Bruno, E., R. J. Cooper., R. A. Briddell, and R. Hoffman. 1991. Further examination of the effects of recombinant cytokines on the proliferation of human megakaryocytes progenitor cells. Blood. 77:2339-2346.

24. Debil, N., E. Hegyi, S. Navarro, A. Katz, M. A. Mouthon, B. J. Gorius, and W. Vainchenk. 1991. In vitro effects of hematopoietic growth factors on the proliferation, endoreplication, and maturation of human megakaryocytes. Blood. 77:2326-2338

25. Gasner, A., G. Seipelt, A. Lindemann, O. G. Ottmann, M. Eder, F. Herrmann, R. Becher, K. Hoffken, and T. Buchner. 1990. Effects of recombinant human interleukin-3 in patients with myelodysplastic syndrome. Blood. 76:45562.

26. Gasner, A., G. Seipelt, A. Lindemann, O. G. Ottmann, F. Herrmann, M. Eder, J. Frisch, G. Schulz, R. Mertelsmann, and D. Hoelzer. 1990. Effects of recombinant human Interleukin-3 in patients with bone marrow failure. Blood. 76:666-676.

27. Kurzrock, R., M. Talpaz., Z. Estrov., M. G. Rosenblum, and J. U. Guterman. 1991. Phase I study of recombinant human Interleukin-3 in patients with bone marrow failure. J. Clin. Oncol. 9:1241-1250. 